\title{
Vitamin-D in Nepal: are we really vitamin-D deficient?
}

Avinash Chandra ( $\nabla$ chandraavi@gmail.com )

Annapurna Neurological Institute and Allied Sciences https://orcid.org/0000-0002-3895-5369

\section{Basant Pant}

Annapurna Neurological Institute and Allied Sciences

\section{Reema Rajbhandari}

Annapurna Neurological Institute and Allied Sciences

\section{Sharad Gajuryal}

Annapurna Neurological Institute and Allied Sciences

\section{Pranay Shrestha}

Annapurna Neurological Institute and Allied Sciences

\section{Samir Acharya}

Annapurna Neurological Institute and Allied Sciences

\section{Pravesh Rajbhandari}

Annapurna Neurological Institute and Allied Sciences

\section{Resha Shrestha}

Annapurna Neurological Institute and Allied Sciences

\section{Sujat Dahal}

Annapurna Neurological Institute and Allied Sciences

\section{Research article}

Keywords: Serum vitamin D, Neurological disorder, Deficiency, Incidence.

Posted Date: June 9th, 2020

DOI: https://doi.org/10.21203/rs.3.rs-31374/v1

License: (c) (i) This work is licensed under a Creative Commons Attribution 4.0 International License. Read Full License 


\section{Abstract}

Background: Recently, there have been a surge in research worldwide regarding relation of vitamin D with several diseases. Many neurological diseases like multiple sclerosis, Alzheimer's disease as well as other diseases like cardiovascular disease have shown positive correlation with vit. D deficiency measured according to the international level. Most of the research on possible role of vitamin $\mathrm{D}$ has been carried out in America and European nations, while there is paucity of research in low- and middle-income nations (LMICS) that are nearer to the equatorial area. In countries like Nepal, geographically they lie near to the equator and sunlight exposure is well enough and milk consumption is quite moderate. Thus, special consideration for vitamin D level in Asian population seems plausible. This will not only help us to cover the vitamin D deficient population but will help us to avoid excessive and unnecessary usage of it.

Objectives: This study aims to detect the situation of vitamin D in Nepalese population and secondly to find out the suitable normalized reference range for serum vitamin D in multi-ethnic Nepalese population.

Methodology: This was a hospital based prospective study. A prospective study was conducted using purposive sampling technique with in-vivo and in vitro bio-physiological method to collect serum vitamin D level. After rigorous inclusive and exclusive criteria, a total of 107 subjects were collected.

Result: The present study showed that $32 \%$ of participants had deficit serum Vitamin-D level $(<15 \mathrm{ng} / \mathrm{mL}), 48 \%$ of subjects had insufficient serum level of Vitamin-D $(15-<30 \mathrm{ng} / \mathrm{mL})$ and $20 \%$ of participants had sufficient serum level of Vitamin-D $(>30 \mathrm{ng} / \mathrm{mL})$. Study showed that there is lower degree of positive relationship of Body Mass Index (BMI) with Serum Vitamin-D level $(r=0.162$, $p=0.094)$, History of chronic illness $(\chi 2=0.10, p=0.03)$, timing of occurrence of stroke $(\chi 2=11.41, p=0.017)$ and diagnosis $(\chi 2=21.19$, $p=0.011$ ) had significant association with Serum vitamin-D level at $p<0.05$.

Conclusion: There is direct significant association of Serum Vitamin D with socio-demographic variables when international unit is considered. Neurological disorder showed positive association with serum vitamin D level.

\section{Background}

Research of Vitamin D in neurology has gained momentum recently. Many neurological ailments like multiple sclerosis ${ }^{1}$, spinal diseases, Alzheimer's disease ${ }^{2}$ as well as other diseases like cardiovascular disease ${ }^{3}$ have shown positive correlation with vitamin D deficiency. Probably this is one of the main reasons that family physicians and neurologists have opted for including serum vitamin $\mathrm{D}$ in their lab investigation. However, the reference range that is followed in all over the world comes from the western world consisting of data largely based on caucasian population and measurement and clinical interpretation is done on the basis of this reference level. ${ }^{4,5}$

Vitamin $D$ is a group of fat-soluble prohormones which were identified after the discovery of the anti-rachitic effect of cod liver oil in the early part of the $20^{\text {th }}$ century. The two major biologically inert precursors of vitamin D are vitamin D3 (cholecalciferol) and vitamin D2 (ergocalciferol). Both vitamin D precursors resulting from exposure to the sunshine and the diet are converted to 25hydroxyvitamin $\mathrm{D}[25(\mathrm{OH}) \mathrm{D}]$ (calcitriol) when they enter the liver. $25(\mathrm{OH}) \mathrm{D}$ is the major circulating form of vitamin $\mathrm{D}$ and is used to determine vitamin D status Vitamin D has several roles in the body, including modulation of cell growth, neuromuscular and immune function, and reduction of inflammation. Many genes encoding proteins that regulate cell proliferation, differentiation, and apoptosis are modulated in part by vitamin $D .6,7$

Despite the numerous studies about the association between vitamin D and different health outcomes, there are still controversies defining the adequate vitamin D status, daily intake needed and the potential adverse health consequences of its deficiency. Serum 25-hydroxy vitamin D concentrations are being used to define vitamin D deficiency, but the diagnostic test accuracy of these measurements and the reference standard used are not clearly stated. There appears to be a wide variability between different essays for its determination in different laboratories and there is not yet international consensus on the optimal concentrations in different population groups. ${ }^{8}$ 
According to the epidemiologic studies, based on the internationally accepted serum vitamin $\mathrm{D}$ levels, about 1 billion people worldwide have vitamin D deficiency, while $50 \%$ of the population has vitamin D insufficiency. ${ }^{9}$ The prevalence of patients with vitamin D deficiency is highest in the elderly, the obese patients, nursing home residents, and hospitalized patients. Prevalence of vitamin D deficiency was $35 \%$ higher in obese subjects irrespective of latitude and age. ${ }^{10}$

In South-Asian region $80 \%$ of the apparently healthy population is deficient in vitamin D and up to $40 \%$ of the population is severely deficient when considered according to the international level. ${ }^{11}$ A study on hypovitaminosis $\mathrm{D}$ in developing countries to assess prevalence, risk factors and outcomes revealed that though South Asia region has ultra violet B (UVB) radiation levels that are sufficient for vitamin $D$ synthesis for 11 to 12 months of the years, however, serum 25-hydroxyvitamin $D$ levels of $<25 \mathrm{nmol} / /$ have been reported in more than $50 \%$ of the infant, children and women. ${ }^{12}$

Another study conducted on prevalence of Vitamin D deficiency among adult patients in a tertiary care hospital in Nepal has reported that out of total patients, vitamin D deficiency was found among total of 283 patients. Vitamin D deficiency was found to be higher in females than males. ${ }^{13}$

Neurological disorders are an important cause of disability and death worldwide. Globally, the burden of neurological disorders has increased substantially over the past 25 years because of expanding population numbers and growing ageing, despite substantial decreases in mortality rates from stroke and communicable neurological disorders. ${ }^{14}$ A systemic analysis for global, regional and national burden of neurological disorders during 1990-2016 stated that globally, in 2016, neurological disorders ranked as the leading cause of Disability-Adjusted Life Year (DALYs) in 2016 (i.e. 276 million, comprising 10.2\% of global DALYs) and secondleading cause group of deaths (i.e. 9 million, comprising $16.8 \%$ of global deaths). The four largest contributors of neurological DALYs were Stroke (42.2\%), Migraine (16.3\%), Alzheimer's and other dementias (10.4\%) and meningitis (7.9\%). ${ }^{15}$

As considerable Hypovitaminosis D is common in Asians, physicians often prescribe cholecalciferol at a dose of $60,000 \mathrm{IU} /$ week for two months, then at $60,000 \mathrm{lU} /$ month for six months for occult vitamin D deficiency. ${ }^{16}$ Although this practice is most commonly followed, the adverse effects on excessive supplementation of vitamin D and the high serum 25(OH)D levels in Nepalese individuals have not been systematically studied.

Notably serum vitamin D is inconsistent in diverse population. Even in the homogenous population of caucasians, vitamin D genetic variability in vitamin and calcium receptors has been witnessed. ${ }^{17,18}$ In countries like Nepal, geographically they lie near to the equator and sunlight exposure is well enough. Thus, special consideration for vitamin D level in Asian population seems plausible. This will not only help us to cover the vitamin D deficient population, ${ }^{19,20}$ but will also help us to avoid excessive and unnecessary usage of it. We have sought to find out whether the depletion of vitamin $D$ in our population is for real and if these are of real, do the depletion vitamin D cause the neurological disorders?

\section{Methodology}

\subsection{Subjects}

The purpose of the study was to find out the suitable normalized reference range for serum vitamin $D$ in multi-ethnic Nepalese population and to detect the correlation of vitamin D and Neurological disorders. This is prospective study that includes the quantitative research design selected for the dependent variables i.e. serum Vitamin $D$ level and independent variables i.e. health history, history of chronic illness, types of stroke, smoker and alcohol consumption, physical activity and Basal Metabolic Index (BMI) of subjects, socio-demographic variables such as age, sex, education, marital status and address of subjects. Prospective purposive sampling technique was used. A total of 108 subjects were included. The study was approved by institutional review board (IRB) of our institute and informed written consent was obtained from each participant. The data collection was conducted from $1^{\text {st }}$ September till $1^{\text {st }}$ January. Inclusion and Exclusion criteria were set as the inclusion criteria for present study was the subject with: a) age 18 years and older, b) anyone willing to take part \& c) presence of any neurological disease and d) any healthy person present at the time of data collection. Exclusion criteria were: a) Age below 18 years or above 90 years, b) not giving consent, c) no other chronic illness besides neurological (diabetes, other cancers, gynecologic diseases, hypertension and d) 
anyone taking Calcium or vitamin concentrates or supplements or has been treated for calcium recently or vitamin D supplements (within 30 days).

\subsection{Clinical examination:}

The Socio-demographic variables were measured using structured questionnaire that consists age, sex, educational status, permanent address, marital status of subjects. The part of same questionnaire consisted personal history such as history of stroke, type of stroke, chronic illness, physical activity, smoking habits, and alcohol consumption. All the subjects were examined with physical and neurological examination by experienced physician, and neurologist. In-vivo bio-physiological method was used to measure BMI and In-vitro bio-physiological method was used to quantify level of Vitamin-D using ELISA method with 'Mono Bind Inc.' USA. Radiological measurements were also performed to confirm the neurological disorders.

$\mathrm{BMI}$, formerly called the Quetelet index, is a measure for indicating nutritional status in adults is defined as a person's weight in kilograms divided by the square of the person's height in metres $(\mathrm{kg} / \mathrm{m} 2)$. The level of BMI was distributed as a) $<18.5 \mathrm{~kg} / \mathrm{m}^{2}$ under-weight, b) $18.5-24.9 \mathrm{~kg} / \mathrm{m}^{2}$ normal weight, c) $25-29.9 \mathrm{~kg} / \mathrm{m}^{2}$ over weight and d) $>30 \mathrm{~kg} / \mathrm{m}^{2}$ obesity. ${ }^{21}$ In another hand the level of Vitamin-D was scored as a) $<15 \mathrm{ng} / \mathrm{mLdeficit,} \mathrm{b)} 15-<30 \mathrm{ng} / \mathrm{mL}$ insufficient and c) $>30 \mathrm{ng} / \mathrm{mL}$ sufficient.

\subsection{Statistical Analysis:}

Statistical analysis was performed using the IBM Statistical Package for the Social Sciences (SPSS version 20). A descriptive analysis: frequency, percentage, mean, and standard deviation were used to describe the socio-demographic variables and independent variables. An inferential analysis: Chi-square test, Karl Pearson Correlation Coefficient, Multivariate Linear Regression analysis was used to find association between Level of Vitamin-D and selected socio-demographic variables and Independent variables of Nepalese people. A nominal $p$-value of $\leq 0.05$ was considered statistically significant, and $p<0.1$ was considered a trend, using two-tailed test.

\section{Results}

\subsection{Demographic and Clinical Characteristics}

The demographic characteristics of total 108 eligible subjects are presented in Table1.1, among them more than half i.e. 66\% (71) were male, one third of subjects i.e. $36 \%$ (39) were 46-60years old age group, majority of participants i.e. 76\% (82) were from hilly region, more than half of subjects were i.e. $62 \%$ (67) from inside the Kathmandu valley (capital of Nepal). With regards to education $44 \%$ (48) had received only primary education level (spent few years in school), 89\% (96) participants were married. Majority of the participants i.e. $71 \%$ (77) were active in their life, $28 \%$ (30) were smokers and $29 \%$ (31) were alcohol consumer. Among the participants, $40 \%$ (43) had stroke, among which, more than half 58\% (63) had approached emergency department in less than 24 hours of stroke onset. Presented in table 1.2 majority of subjects i.e. 75\% (81) had chronic illness with hypertension and other condition; similarly, $72 \%$ (78) of participants were suffering with chronic illness since less than 5 years. With regards to types of stroke, $64 \%$ (69) and 36\% (39) had Ischemic and Hemorrhagic stroke, respectively.

Table 1.1: Characteristics of the Study Population

$$
\mathrm{n}=108
$$




\begin{tabular}{|c|c|c|}
\hline & Frequency (Percentages\%) & Mean \pm SD \\
\hline Sex & & $1.34 \pm 0.48$ \\
\hline Male & $71(65.7)$ & \\
\hline Female & $37(34.3)$ & \\
\hline Age & & $61.1 \pm 14.92$ \\
\hline$<45$ years & $16(14.8)$ & \\
\hline $46-60$ years & $39(36.1)$ & \\
\hline 61-75 years & $33(30.6)$ & \\
\hline$>75$ years & $20(18.5)$ & \\
\hline Marital Status & & $2.11 \pm 0.316$ \\
\hline Married & $96(88.9)$ & \\
\hline Unmarried & $12(11.1)$ & \\
\hline Address & & $1.94 \pm 0.49$ \\
\hline Terai/Plain region & $16(14.8)$ & \\
\hline Hilly region & $82(75.9)$ & \\
\hline Mountain region & $10(9.3)$ & \\
\hline Education & & $1.81 \pm 1.148$ \\
\hline Illiterate & $8(7.4)$ & \\
\hline Primary & $48(44.4)$ & \\
\hline Secondary & $20(18.5)$ & \\
\hline Intermediate & $21(19.4)$ & \\
\hline Others & 11(10.3) & \\
\hline Physical Activity & & $1.29 \pm 0.454$ \\
\hline Active & 77(71.3) & \\
\hline Inactive & $31(28.7)$ & \\
\hline Smoke & & $1.72 \pm 0.45$ \\
\hline Smoker & $30(27.8)$ & \\
\hline None Smoker & $78(72.2)$ & \\
\hline Alcohol & & $1.71 \pm 0.454$ \\
\hline Alcoholic & $31(28.7)$ & \\
\hline Non Alcoholic & $77(71.3)$ & \\
\hline
\end{tabular}

Table 1.2: Clinical Characteristics of the Study Population

$n=108$ 


\begin{tabular}{|c|c|c|}
\hline & $\begin{array}{l}\text { Frequency } \\
\text { (Percentages\%) }\end{array}$ & Mean \pm SD \\
\hline Diagnosis & & $5.78 \pm 2.67$ \\
\hline Thalamic hemorrhage & $14(13.0)$ & \\
\hline MCA infract & $6(5.6)$ & \\
\hline Basal Ganglia Ischemia & $7(6.5)$ & \\
\hline Basal Ganglia Infraction & $4(3.7)$ & \\
\hline Basal Ganglia hemorrhage & $17(15.5)$ & \\
\hline Right sided Parietal Ischemia & $10(9.3)$ & \\
\hline Left sided Parietal Ischemia & $34(31.5)$ & \\
\hline Multi infract & $6(5.6)$ & \\
\hline Other Ischemia & 2(1.9) & \\
\hline None & $8(7.4)$ & \\
\hline Health History at the time of Admission & & $2.36 \pm 1.67$ \\
\hline Right sided weakness & $38(35.2)$ & \\
\hline Left sided weakness & $43(39.8)$ & \\
\hline Blurred vision & $4(3.7)$ & \\
\hline Loss Of Consciousness, dizziness \& headache & $9(8.3)$ & \\
\hline Slurred speech & $8(7.4)$ & \\
\hline Unable to recall \&disorientation & $1(0.9)$ & \\
\hline Bilateral weakness \& ABM & $3(2.8)$ & \\
\hline Healthy & $2(1.9)$ & \\
\hline Types of Stroke & & $1.36 \pm 0.48$ \\
\hline Ischemic Stroke & $69(63.9)$ & \\
\hline Hemorrhagic Stroke & $39(36.1)$ & \\
\hline Timing of Stroke before Admission & & $1.59 \pm 0.83$ \\
\hline$<1$ day & $63(58.3)$ & \\
\hline 1-5 days & $31(28.7)$ & \\
\hline $6-10$ days & $9(8.3)$ & \\
\hline 11-15days & $5(4.6)$ & \\
\hline History of Chronic Illness & & $0.75 \pm 0.42$ \\
\hline Hypertension & $27(25.0)$ & \\
\hline Hypertension and other & $81(75.0)$ & \\
\hline Timing/Length of Chronic Illness & & $1.41 \pm 0.789$ \\
\hline 0-5years & $78(72.2)$ & \\
\hline 6-10years & $21(19.4)$ & \\
\hline 11-15years & $5(4.6)$ & \\
\hline 16-20years and more & $4(3.7)$ & \\
\hline
\end{tabular}

\subsection{Incidence of Serum Vitamin D in Nepalese Population and its relationship with BMI}

The status of serum vitamin-D has been presented in table 2. The present study showed that $32 \%$ (34) of participants had deficit serum Vitamin-D level ( $<15 \mathrm{ng} / \mathrm{mL}), 48 \%$ (52) of subjects had insufficient serum level of vitamin-D $(15-<30 \mathrm{ng} / \mathrm{mL})$ and $20 \%$ (22) of participants had sufficient serum level of vitamin-D (>30ng/mL). Majority of participants i.e. $73 \%$ (79) had normal body weight, $22 \%$ (24) of subjects had overweight, $2.8 \%$ (3) were obese and $0.9 \%$ (1) was under weight. The current study stated that there is lower degree of positive relationship of BMI with serum vitamin-D level

$(r=0.162, p=0.094)$, that is statistically not significant at $p<0.05$. In another way there is no statistically significant association between $\mathrm{BMI}$ and vitamin $\mathrm{D}(\chi 2=12.474, p=0.071)$.

Table 2: Prevalence of Serum Vitamin D and BMI among Nepalese Population

\begin{tabular}{|c|c|c|}
\hline & FrequencyPercentages(\%) & Mean \pm SD \\
\hline Level of Serum Vitamin-D & & $21.85 \pm 13.57$ \\
\hline$<15 \mathrm{ng} / \mathrm{mL}$ deficit & $34(31.5)$ & \\
\hline $15-<30 \mathrm{ng} / \mathrm{mLinsufficient}$ & $52(48.1)$ & \\
\hline >30 ng/mLsufficient & $22(20.4)$ & \\
\hline Level of BMI & & $23.63 \pm 2.83$ \\
\hline$<18.5 \mathrm{Kg} / \mathrm{m}^{2}$ under weight & $2(1.8)$ & \\
\hline $18.5-24.9 \mathrm{Kg} / \mathrm{m}^{2}$ normal weight & $79(73.1)$ & \\
\hline $25-29.9 \mathrm{Kg} / \mathrm{m}^{2}$ over weight & $24(22.2)$ & \\
\hline$>30 \mathrm{Kg} / \mathrm{m}^{2}$ obesity & $3(2.8)$ & \\
\hline
\end{tabular}




\subsection{Serum Vitamin-D level and association with Socio-demographic variables and clinical characteristics}

Table3 states the association between serum vitamin-D level and socio-demographic variables. Present study revealed that serum vitamin-D level was significantly associated with gender $(\chi 2=0.233, p=0.003)$, marital status $(\chi 2=0.562, p=0.014)$, address (i.e. Terai which means Plain low land of Nepal, Hilly and Mountainous region) $(\chi 2=4.431, p=0.009)$ and physical activity $(\chi 2=0.193$, $0.013)$. Whereas, there was lower degree of negative relationship of serum vitamin $D$ with gender $(r=0.045, p=0.649)$, marital Status $(r=0.015, p=0.88)$ and positive relation with physical activity $(r=0.111, p=0.25)$ and address $(r=0.12, p=0.27)$. With regards to history of chronic illness $(\chi 2=0.10, p=0.03)$, timing of occurrence of stroke $(\chi 2=11.41, p=0.017)$ and diagnosis $(\chi 2=21.19, p=0.011)$, there was significant association with serum vitamin-D level at $p<0.05$. There was lower degree of positive relation of chronic illness $(r=0.053, p=0.579)$ and diagnosis $(r=0.012, p=0.902)$ with serum Vitamin-D level.

We also observed a poor level of positive relation of smoker $(r=0.02, p=0.805)$ and alcoholism $(r=0.059, p=0.534)$ with serum vitamin D level, but statistically not significant. Smoke $(\chi 2=0.355, p=0.048)$ was significantly associated with serum level of vitamin-D. The serum vitamin-D level was not significantly associated with age $(\chi 2=0.64, p=0.09)$, educational status $(\chi 2=11.54$, $p=0.21)$, history of stroke $(\chi 2=11.62, p=0.06)$ and type of stroke $(\chi 2=4.84, p=0.21)$ at $p=0.05$.

Table 3: Association of Vitamin-D with Socio-demographic variables

\begin{tabular}{|c|c|c|c|c|}
\hline \multicolumn{5}{|c|}{$\mathrm{n}=108$} \\
\hline & Chisquare $(\chi 2)$ & P-value & Karl-pearson Coefficient correlation (r) & p-value \\
\hline Sex & $0.23^{\#}$ & 0.003 & $-0.045 *$ & 0.65 \\
\hline Age & 0.64 & 0.090 & 0.039 & 0.68 \\
\hline Marital Status & $0.56^{\#}$ & 0.014 & $-0.015^{*}$ & 0.88 \\
\hline Address & $4.43^{\#}$ & 0.009 & 0.12 & 0.27 \\
\hline Education & 11.54 & 0.210 & $-0.183 *$ & 0.06 \\
\hline Physical Activity & $0.19^{\#}$ & 0.013 & 0.111 & 0.25 \\
\hline Smoke & $0.36^{\#}$ & 0.048 & 0.02 & 0.81 \\
\hline Alcohol & 4.12 & 0.189 & 0.059 & 0.53 \\
\hline Diagnosis & $21.19^{\#}$ & 0.011 & 0.012 & 0.90 \\
\hline History of Stroke at the time of Admission & 11.62 & 0.060 & 0.032 & 0.22 \\
\hline Types of Stroke & 4.84 & 0.210 & $-0.121 *$ & .21 \\
\hline Timing of Stroke before Admission & $11.41^{\#}$ & 0.017 & 0.031786 & 0.24 \\
\hline History of Chronic Illness & $0.10^{\#}$ & 0.030 & 0.053 & 0.58 \\
\hline Timing/Length of Chronic Illness & $8.07^{\#}$ & 0.120 & 0.115 & 0.24 \\
\hline BMI & 12.47 & 0.071 & 0.162 & 0.09 \\
\hline
\end{tabular}

Note: $\mathrm{BMI}=$ Body mass index, $\#=$ Significantly associated, $*=$ negative relation

\section{Discussion}

Vitamin D deficiency has been mechanistically and clinically linked to neurological diseases and neuropsychological disorders, cognitive impairment, and neurodegenerative diseases. ${ }^{22}$ Our current study has emphasized that $32 \%$ of participants had deficit serum Vitamin-D level, $48 \%$ of subjects had insufficient and $20 \%$ of participants had sufficient serum level of vitamin-D.

Studies carried across different countries in South and South East Asia showed, with few exceptions, widespread prevalence of hypovitaminosis $D$, in both sexes and all age groups of the population. ${ }^{23}$ High prevalence of hypovitaminosis $D$ in South Asia can be explained by skin pigmentation and traditional clothing. Air pollution and limited outdoor activity further compounds this problem in the urban population. ${ }^{24}$ The current study stated that there is lower degree of positive relationship of BMI with Serum Vitamin-D level $(r=0.162, p=0.094)$, that is statistically not significant at $p<0.05$. In another way there is no statistically significant association between $\mathrm{BMI}$ and vitamin $\mathrm{D}(\chi 2=12.474, p=0.071)$. The finding is supported by a study on the effect of vitamin $D$ supplementation on serum $250 \mathrm{HD}$ in thin and obese women as the result showed a significant inverse relation between total body fat mass and serum 25-OHD $(p<0.0001)$ and serum $1,25(\mathrm{OH})_{2} \mathrm{D}(p=034)$. There was no significant change in total body fat mass after treatment with vitamin $\mathrm{D}$ or calcitriol in randomized trials. ${ }^{25}$ Similarly the finding is contradicted by the study aimed to find 
association between $\mathrm{BMI}$ and vitamin $\mathrm{D}$ supplement the result stated that there was significant differences in mean $25(\mathrm{OH}) \mathrm{D}$ levels of vitamin D supplementation doses were consistently seen across BMI categories. ${ }^{26}$ Again contradicted by another crosssectional study on serum vitamin D level in different 222 socio-demographic population The mean difference between normal and obese population was statistically significant $(p=0.007) .{ }^{27}$

Present study revealed that serum vitamin-D level was significantly associated with gender $(\chi 2=0.233, p=0.003)$, marital status $(\chi 2=0.562, p=0.014)$, address (i.e. Terai, Hilly and mountain region) $(\chi 2=4.431, p=0.009)$ and physical activity $(\chi 2=0.193,0.013)$. Several national and international previous studies supported the finding as an ecological study conducted to assess association of vitamin D status with socio-demographic factors in Calgary, Canada, result of the study revealed that there is significant association between 25-hydroxyvitaminD level and all the predictors i.e. age, gender and educational status (all $p<0.0001$ ). ${ }^{28}$ Another study on determinants of vitamin D status in young adults; influence of lifestyle, sociodemographic and anthropometric factors among 738 subjects revealed that the relative risk (RR) for vitamin D deficiency was highest for men 2.09 (1.52, 2.87); subjects who exercised $0-1 / 2$ hours a week $1.88(1.21,2.94) .{ }^{29}$ A study aimed to assess the association between vitamin D deficiency and depression in Nepalese population stated significant association of gender, geographical location of residence, marital status, religion and vitamin D status with clinically significant depression. ${ }^{30}$ Other study has been observed a direct relationship between latitude and the prevalence of Multiple Sclerosis (MS), which suggests a role for UV radiation and vitamin D in MS development. ${ }^{31}$

There was poor level of positive relation of Smoker $(r=0.02, p=0.805$ and Alcoholism $(r=0.059, p=0.534)$ with serum vitamin $D$ level, but statistically not significant. Smoke $(\chi 2=0.355, p=0.048)$ was significantly associated with serum level of vitamin-D whereas no association of alcohol with vitamin-D level at $p<0.05$. A cross-sectional study on determinants of vitamin $D$ status in young adults; influence of lifestyle, sociodemographic and anthropometric factors among 738 subjects supports as the result of study revealed that 238 subjects had vitamin D insufficiency, 135 had vitamin D deficiency of which 13 had severe vitamin D deficiency (S$25[\mathrm{OH}] \mathrm{D}<12.5 \mathrm{nmol} / \mathrm{L})$. The relative risk $(R R)$ for vitamin $\mathrm{D}$ deficiency was highest for smokers $1.33(1.02,1.73)$. Smoking was associated with a higher $R R=1.33(1.02,1.73)$ for vitamin $\mathrm{D}$ deficiency compared with nonsmoking. Whereas contradicted the result of alcohol as alcohol intake was associated with a lower $R R=0.68(0.47,0.90)$ for vitamin $D$ deficiency compared to nondrinker, an increase of one unit of alcohol was associated with $R R=0.81(0.68-0.97) .{ }^{29}$ Another study on interaction of vitamin $\mathrm{D}$ and smoking on inflammatory markers, the data was collected from Korean Elderly Environmental Panel Study that included 560 subjects. The result of the study was that association of vitamin D deficiency and hs-CRP in smokers was stronger than that in nonsmokers (smokers: $\beta=-0.375, p=0.013$; non-smokers: $\beta=-0.060, p=0.150$ ). Smoking status was an effect modifier that changed the association between vitamin D deficiency and hs-CRP (interaction estimate: $\beta=-0.254, p=0.032$ ). There was a stronger significant association of smokers and vitamin D deficiency than non-smokers. ${ }^{32} \mathrm{~A}$ review on Vitamin $\mathrm{D}$ and alcohol aimed to evaluate the association between alcohol use and vitamin $D$ serum levels alcohol intake was found to be positively associated with vitamin D status in 15 articles and negatively associated with vitamin D in 18 articles. ${ }^{33}$ the finding is contradicted by another study on chronic ethanol exposure effects on vitamin D levels among subjects with alcohol use disorder stated that levels of inactive vitamin $\mathrm{D}\left(25(\mathrm{OH}) \mathrm{D}_{3}\right)$, active vitamin $\mathrm{D}\left(1,25(\mathrm{OH})_{2} \mathrm{D}_{3}\right)$, cathelicidin/LL-37, and CYP27B1 proteins were significantly reduced $(p<0.05)$. Chronic exposure to alcohol has the potential to reduce the levels of vitamin D. ${ }^{34}$

Several evidence suggests that vitamin D acts like a neurosteroid and is required for normal brain development and function. ${ }^{35}$ An endocrine review on Vitamin $\mathrm{D}$ and neurological diseases, aimed to highlight the relationship between vitamin $\mathrm{D}$ and neurological diseases stated that there is association between low levels of $25(\mathrm{OH}) \mathrm{D}$ and a wide spectrum of neurodegenerative conditions such as multiple sclerosis, Alzheimer's disease, Parkinsons's disease and neurocognitive disorders, is supported by in vitro and in vivo data. ${ }^{35}$ Other studies showed that the risk of MS decreases with increasing intake of vitamin $D^{36}$, and serum 25(OH)D levels are significantly lower in patients with MS as compared to healthy controls. ${ }^{37}$ These studies directly support the results of our current study as history of chronic illness $(\chi 2=0.10, p=0.03)$, timing of occurrence of stroke $(\chi 2=11.41, p=0.017)$ and diagnosis $(\chi 2=21.19, p=0.011)$ had significant association with Serum vitamin-D level at $p<0.05$. There was lower degree of positive relation of chronic illness $(r=0.053, p=0.579)$ and diagnosis $(r=0.012, p=0.902)$ with serum Vitamin-D level. Whereas the Serum Vitamin-D level was not significantly associated with History of stroke $(\chi 2=11.62, p=0.06)$ and type of stroke $(\chi 2=4.84, p=0.21)$ at $p=0.05$. 
Another cross-sectional study to evaluate the association between Vitamin-D and hypertension among 520 people supports the study as the result stated that Severe vitamin D deficiency was highly prevalent in people with hypertension than in people without hypertension ( $p$ value $<0.001)$. The study concluded that Vitamin $D$ deficiency was associated with an increased risk of having hypertension ${ }^{38}$ In our current study subjects $25 \%$ (27) had chronic illness history with hypertension and the Karl pearson correlation coefficient showed positive relation as well significant association with Serum Vitamin D level of Nepalese residents. A Similar Case-control study aimed to assess the serum level of vitamin D in cerebral stroke patients and secondly, to examine if its deficiency was associated with stroke severity and outcome result revealed that studied stroke patients had statistically significant lower levels of vitamin D. Multivariable analysis of the significant variables showed that old age $(O R=1.072)$, dyslipidemia $(O R=$ 3.588), vitamin $D$ deficiency $(O R=4.790)$, and large infarction size $(O R=7.462)$ was independently associated with stroke severity. The study concluded that stroke patients suffer from vitamin D deficiency, which was associated with both stroke severity and poor outcome. ${ }^{39}$

A study on reduced Vitamin $D$ in acute stroke compared the serum 25-dihydroxyvitamin D levels with first-ever stroke the result revealed no relationship between $250 \mathrm{HD}$ level and the length of time between stroke and 250HD sampling (adjusted $\left.r^{2}=-0.02 ; P=0.77\right)$. The mean $Z$ score of vitamin $D$ in acute stroke was $-1.4 S D$ units $(95 \% \mathrm{Cl},-1.7,-1.1)$, with $77 \%$ of patients falling in the insufficient range concluded that reduced vitamin $D$ was identified in the majority of patients with acute stroke throughout the year and may have preceded stroke. ${ }^{40} \mathrm{~A}$ vitamin $\mathrm{D}$ deficiency and incident stroke risk in community living black and white, supports the finding as the study revealed there was no statistically significant differences in the association of lower 25-hydroxyvitamin D with higher risk of stroke in black i.e. $(95 \% C l 1.18,5.83)$ vs. white i.e. $(95 \% C / 0.83,3.24)$ participants. ${ }^{41}$ Another study on Vitamin D in amyotrophic lateral sclerosis represented that in chronic neurological diseases levels of vitamin $D$ in blood appeared low but there was no significant differences found between the level of vitamin $D$ and Amyotrophic lateral sclerosis patients $(18.8 \pm 12.2)$ and the healthy subjects $(20.7 \pm 10.1) .{ }^{42}$ Similarly, Cross-sectional associations of plasma vitamin $D$ with cerebral $\beta$-amyloid in older adults at risk of dementia, the study didn't find the association between baseline $25(\mathrm{OH}) \mathrm{D}$ levels and cerebral $A \beta$ in any of the brain regions studied. ${ }^{43}$ Vitamin $D$ is not associated with incident dementia or cognitive impairment over an 18 years period of time another study presented as the result showed that the adjusted HR for the continuous GRS for all

cause dementia was $1.04(95 \% \mathrm{Cl}: 0.91,1.19) .{ }^{44} \mathrm{~A}$ study to investigate association between serum concentration of vitamin $\mathrm{D}$ and 1-year mortality in stroke patients presents that out of the 382 stroke patients, $16.5 \%$ died in a year, and the mean $25(\mathrm{OH}) \mathrm{D}$ level was lower in those patients $(32.3 \pm 22.0 \mathrm{vs.} 44.6 \pm 28.7 \mathrm{nmol} / \mathrm{l}, \mathrm{p}<0.001)$ and survival at 1 year was worse in patients in the lowest tertile of $25(\mathrm{OH}) \mathrm{D}$ levels (i.e. $<25.7 \mathrm{nmol} / \mathrm{l})$. The study concluded that low level serum $25(\mathrm{OH}) \mathrm{D}$ level at stroke onset association was with higher mortality at 1 year in patient. ${ }^{45}$

The finding from this study may supports for the implementation of measures to determine the real state of vitamin $D$ and its implication on Neurological disorders. We recognize some limitations of our study as the study completed with small size of 108 due to rigorous inclusion and exclusion criteria. As it was a hospital-based study, sample might not be enough to represent the total population of our country. The study should be continued with similar control groups.

\section{Conclusion}

Despite abundant sunlight in Nepal several studies suggest the prevalence of Vitamin D deficiency in this region. Our question is whether the reference given globally is accurate for the land-locked country with different geographical area, multi-cultural, religion and practices. Through the study we concluded that more than half of population having Serum Vitamin-D insufficiency. Level of serum vitamin-D is significantly associated with socio-demographic variables as well with neurological conditions but there are lots of caveats with it. A larger population-based study in multinational (equatorial region) seems necessary.

\section{List Of Abbreviations}

WHO= World Health Organization

$\mathrm{BMI}=$ Body Mass Index

MS= Multiple Sclerosis

Page $9 / 12$ 


\section{Declarations}

\section{Ethics approval and consent to participate}

Annapurna Institutional Review Board of Annapurna Neurological Institute and Allied Sciences approved this study.

\section{Consent to participate}

The participants were well informed about the study. The participants were well informed in written and well explained and obtained consent to participate.

\section{Consent for publication}

Not Applicable

\section{Author's Contribution}

All authors have made a substantial contribution to this paper.

AC contributed to the conceptualization and drafting of the article. BP and SD contributed to conceptualization of manuscript. RR and SG contributed to the study design and SA contributed to the revision of the article. PR, PS and RS contributed to the statistical analysis.

\section{Competing Interests}

None to declare.

\section{Funding}

Not available

\section{Acknowledgement}

We acknowledge Ms. Pooja Prakash for her immense help in language and editing of this paper.

\section{Availability of data and materials}

The availability of data and materials is provided in supplementary file

\section{References}

1. Ascherio A, Munger KL, White R, et al. Vitamin D as an early predictor of multiple sclerosis activity and progression. JAMA Neurol 2014;71:306-314.

2. Annweiler C. Vitamin D in dementia prevention. Ann N Y Acad Sci 2016;1367:57-63.

3. Chung M, Balk EM, Brendel M, et al. Vitamin D and calcium: a systematic review of health outcomes. Evid Rep Technol Assess (Full Rep) 2009:1-420.

4. Holick MF. Vitamin D status: measurement, interpretation, and clinical application. Ann Epidemiol 2009;19:73-78.

5. Ross AC, Manson JE, Abrams SA, et al. The 2011 report on dietary reference intakes for calcium and vitamin $D$ from the Institute of Medicine: what clinicians need to know. J Clin Endocrinol Metab 2011;96:53-58.

6. Taylor C.L, Yaktine A.L.and Valle H.B. D. Dietary Reference Intakes for Calcium and Vitamin D. Institute of Medicine (US) committee, Food and Nutrition Board.. Washington, DC: National Academy Press(US); 2011. Available from: https://www.ncbi.nlm.nih.gov/books/NBK56070/doi: 10.17226/13050

7. Cranney A, Horsley T., O'Donnell S, Weiler $\mathrm{H}$ and Puil $\mathrm{L}$ et al. Effectiveness and safety of vitamin $\mathrm{D}$ in relation to bone health. Agency for Healthcare Research and Quality, 2007. Available from: https://www.ncbi.nlm.nih.gov/books/NBK74011/. 
8. Vitamin D nutrition with a focus on the prevention of rickets and vitamin D deficiency in pregnant women. Workshop Executive Committee. World Health Organization;2015. Available from:

https://www.who.int/nutrition/events/2015_vit_d_workshop_pregnantwomen_21to24Apr15/en/.

9. Nair R, Maseeh A. Vitamin D: The "sunshine" vitamin. J Pharmacol Pharmacother. 2012 Apr;3(2):118-26.

10. Pereira-Santos M, Costa PR, Assis AM, Santos CA, Santos DB. Obesity and vitamin D deficiency: a systematic review and meta-analysis. Obes Rev;16(4):341-9. Available from: https://pubmed.ncbi.nlm.nih.gov/25688659/.

11. Arya V, Bhambari R, Godbole MM, Mithal A. Vitamin D status and its relationship with bone mineral densitary in healthy Asian Indians. Osteoporosis Int 2004; 15(1): 56-61.

12. Arabi A, Rassi R Eand Fuleihan E.H.G. Hypovitaminosis D in developing countries- prevalence, risk factors and outcomes. Nat. Rev. Endocrinol;2010.6, 550-561 .doi:10.1038/nrendo.2010.146.

13. Shrestha B, Sapkota J and Das J.K. Prevalence of vitamin D deficiency among adult patients in a tertiary care hospital.J Nepal Med Assoc;2019. 57(218):226-28. [cited April22]. Available from:

https://www.jnma.com.np/jnma/index.php/jnma/article/view/4534/2898

14. Feigin V, Nichols E, Alam T. et all. Global, regional, and national burden of neurological disorders during 1990-2015: a systematic analysis for the Global Burden of Disease Study 2015. The lancet Neurology;2015.18(4):459-80. Available from: https://www.researchgate.net/publication/331791871_Global_regional_and_national_burden_of_neurological_disorders_19902016_a_systematic_analysis_for_the_Global_Burden_of_Disease_Study_2016

15. Feigin V.L, Nichols E. et all. Global, regional and national burden of neurological disorders, 1990-2016: a systematic analysis for the global burden of disease study 2016. The lancet Neurology;2019.18(5):459-80. Available from: https://www.sciencedirect.com/science/article/pii/S147444221830499X.

16. Giri M, Upreti B, Joshi R, Rai J.C. and Vaidya B. Efficacy of high dose vitamin D supplementation in improving serum 25hydroxyvitamin D among laboratory personnel working at the Nepal national Centre for Rheumatic diseases. Biomed Rep;2017. 7(6):543-46. doi: 3892/br.2017.1000. Available from: https://www.ncbi.nlm.nih.gov/pmc/articles/PMC5702969/.

17. Garcia-Bailo B, Jamnik J, Da Costa LA, Badawi A, El-Sohemy A. Genetic variation in the vitamin D receptor, plasma 25hydroxyvitamin $D$, and biomarkers of cardiometabolic disease in Caucasian young adults. J Nutrigenet Nutrigenomics 2013;6:256-267.

18. Hansen JG, Gao W, Dupuis J, et al. Association of 25-Hydroxyvitamin D status and genetic variation in the vitamin D metabolic pathway with FEV1 in the Framingham Heart Study. Respir Res 2015;16:81.

19. Prentice RL, Pettinger MB, Jackson RD, et al. Health risks and benefits from calcium and vitamin D supplementation: Women's Health Initiative clinical trial and cohort study. Osteoporos Int 2013;24:567-580.

20. Akhtar S. Vitamin D Status of South Asian Populations- Risks and Opportunities. Crit Rev Food Sci Nutr 2015:0.

21. Body Mass Index-BMI. World Health Organization. Available from: http://www.euro.who.int/en/health-topics/diseaseprevention/nutrition/a-healthy-lifestyle/body-mass-index-bmi.

22. Cui X, Gooch H, Petty A, McGrath J.J and Eyles D. Vitamin D and the brain: Genomic and non-genomic actions. Mol. Cell. Endocrinol; 2017. 453:131-143.

23. Mithal A, Wahl D.A. et.al.Global vitamin D status and determinants of hypovitaminosis D. osteoporosis international;2009.20(11). DOI: 10.1007/s00198-009-1030-y.

24. Malhotra N.and Mithal A. Vitamin D status in Asia. International osteoporosis foundation;2009. Available from: https://www.iofbonehealth.org/sites/default/files/PDFs/Vitamin_D_Asia.pdf.

25. Camozzi V, Frigo AC, Zaninotto M, et al.25-Hydroxycholecalciferol response to single oral cholecalciferol loading in the normal weight, overweight, and obese. Osteoporos Int. 2016;27:2593-2602.

26. Muacevic A. and Adler J.R. The association between body mass index and vitaminD supplement use among adults in the United States. Cureus;2019.11(9):e5721. doi: 7759/cureus.5721. [Cited April25].Available from: https://www.ncbi.nlm.nih.gov/pmc/articles/PMC6823089/

27. Hossain H.T, IslamQ.T, Khandaker A.K. and AhasanH.N. Study of serum vitaminD levelin different socio-demographic population- a pilot study. Jmedicine;2018.19(1):22-29. Available from: 
https://www.banglajol.info/index.php/JOM/article/view/34836.

28. Naugler C, Zhang J, Henne D, Woods P and Hemmelgarn B.R. Association of vitamin D status with socio-demographic factors in Calgary, Alberta: an ecological study using census Canada data.BMC public health;2013.316. Available from: https://bmcpublichealth.biomedcentral.com/articles/10.1186/1471-2458-13-316.

29. Tonnesen R, Hovind P.H, Jensen L.T and Schwarz P. Determinants of vitamin D status in young adults: influence of life style, sociodemographic and anthropometric factors. BMC public health; 2016.16:385. DOI 10.1186/s12889-016-3042-9. Available from: https://link.springer.com/content/pdf/10.1186/s12889-016-3042-9.pdf.

30. Sherchand O, Sapkota N, ChaudhariR.K and Khan S.A. Association between vitamin D deficiency and depression in Nepalese population. Psychiatry Research;2018. DOI: 1016/j.psychres.2018.06.018.

31. Simpson S, Blizzard L, Otahal, P et.al. Latitude is significantly associated with the prevalence of multiple sclerosis: A metaanalysis. J. Neurol. Neurosurg. Psychiatry; 2011. 82:1132-1141.

32. Lee H, Kim Y.H and Hong Y.C.Interaction of vitamin D and smoking on inflammatory markers in the Urban Elderly.J Prev Med Public Health;2015.48(5):249-256. doi: 3961/jpmph.15.042.

33. Tardelli V.S, Lago M.P.P.D, Silveira D.X.D. and Fidalgo T.M. Vitamin D and Alcohol: A review of the current literature. Ormat;2017.248:83-86. doi: 10.1016/j.psychres.2016.10.051

34. Ogunsakin O, Hottor T, Mehta A, Lichtveld M and Mccaskill M. Chronic ethanol exposure effects on vitamin D levels among subjects with Alcohol use disorder. Environ Health Insight;2016.10:191-99. doi: 4137/EHI.S40335

35. Somma C.D, Scarano E, BarreaL, Zhukouskaya V.V.et al. Review vitamin D and neurological diseases:an endocrine view.Int J Mol Sci;2017.18(11):2482. . doi: 3390/ijms18112482.

36. Munger, K.L.; Zhang, S.M.; O’Reilly, E.; Hernan Olek, M.J.; Willett, W.C.; Ascherio, A. Vitamin D intake and incidence of multiple sclerosis. Neurology; 2004. 62:60-65.

37. Mazdeh, M.; Seifirad, S.; Kazemi, N.; Seifrabie, M.A.; Dehghan, A.; Abbasi, H. Comparison of vitaminD3 serum levels in new diagnosed patients with multiple sclerosis versus their healthy relatives. Acta Med. Iran; 2013. 51: 289-292.

38. Vatakencherry R.M.and Saraswathy L. Association between vitamin D and hypertension in people coming for health check up to a tertiary care centre in South India. J family Med Prim Care;2019.8(6):2061-67. doi: 4103/jfmpc.jfmpc_236_19. Available from: https://www.ncbi.nlm.nih.gov/pmc/articles/PMC6618207/

39. Selim et al. Serum vitamin D levels in acute stroke patients. The Egyptian J Neurology;2019.55:80. Available from: https://ejnpn.springeropen.com/articles/10.1186/s41983-019-0129-0.

40. Chaudhuri J.R, Mridula R, Alladi S. et all. Serum 25-hydroxyvitamin D deficiency in Ischemic stroke and subtype in Indian patient. J stroke;2014.16(1):44-50. doi: 10.5853/jos.2014.16.1.44. Available from:

https://www.ncbi.nlm.nih.gov/pmc/articles/PMC3961818/.

41. Judd S.E., Morgan C.J, Panwar B, Howard V.J. et al. Vitamin D Deficiency and incident stroke risk in community living black and white adults. 2016.11(1);93-102. Available from: https://pubmed.ncbi.nlm.nih.gov/26763025/.

42. Libonati L, Onesti E, Gori M.C et al. Vitamin D amyotrophic lateral sclerosis.J F Neur;2017.32(1):35-40. doi: 11138/FNeur/2017.32.1.035. Available from: https://www.ncbi.nlm.nih.gov/pmc/articles/PMC5505528/.

43. Nourhashemi F, Hooper C, Cantet C. et al. Cross-sectional association of plasma vitamin D with cerebral of $\beta$-amloid in older adults at risk of dementia.2018.25;10(1):43. doi: 10.1186/s13195-018-0371-1

44. Olsson E, Byberg L, Karlstrom B. et all Vitamin D is not associated with incident dementia or cognitive impairment: an 18-y follow up study in community- living old men. Ajcn;2017.105(4):936-43. doi: 10.3945/ajcn.116.141531.

45. Daubail B, Jacquin A, Guilland J. et al. Association between serum concentration of vitaminD and 1 year mortality in stroke patients. DOI: 3945/ajcn.116.141531. Available from: https://pubmed.ncbi.nlm.nih.gov/28202477/.

\section{Supplementary Files}

This is a list of supplementary files associated with this preprint. Click to download.

- tableVitD.docx

Page $12 / 12$ 